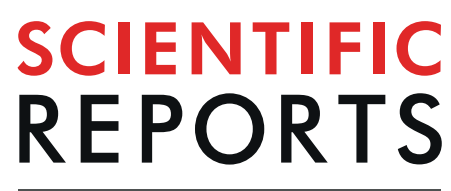

natureresearch

\title{
Systematic Modification of Zingerone Reveals Structural Requirements for Attraction of Jarvis's Fruit Fly
}

\author{
Benjamin L. Hanssen ${ }^{1}$, Soo Jean Park ${ }^{1}$, Jane E. Royer ${ }^{2}$, Joanne F. Jamie ${ }^{1}$, Phillip W. Taylor ${ }^{3} \&$ \\ Ian M. Jamie ${ }^{1^{\star}}$
}

Tephritid fruit flies are amongst the most significant horticultural pests globally and male chemical lures are important for monitoring and control. Zingerone has emerged as a unique male fruit fly lure that can attract dacine fruit flies that are weakly or non-responsive to methyl eugenol and cuelure. However, the key features of zingerone that mediate this attraction are unknown. As Jarvis's fruit fly, Bactrocera jarvisi (Tryon), is strongly attracted to zingerone, we evaluated the response of $B$. jarvisi to 37 zingerone analogues in a series of field trials to elucidate the functional groups involved in attraction. The most attractive analogues were alkoxy derivatives, with isopropoxy being the most attractive, followed by ethoxy and trifluoromethoxy analogues. All of the phenolic esters tested were also attractive with the response typically decreasing with increasing size of the ester. Results indicate that the carbonyl group, methoxy group, and phenol of zingerone are key sites for the attraction of $B$. jarvisi and identify some constraints on the range of structural modifications that can be made to zingerone without compromising attraction. These findings are important for future work in developing and optimising novel male chemical lures for fruit flies.

Males of many dacine fruit flies (Bactrocera Macquart, Zeugodacus Hendel, and Dacus Fabricius) are attracted to specific secondary metabolites produced by some plants and to analogues of these compounds ${ }^{1,2}$. The reason for the attraction of male fruit flies to these compounds, commonly referred to as male lures, attractants, or parapheromones, is generally considered to be related to mating success ${ }^{1,3}$. When males feed on these natural lures, the ingested lure compound is transported and stored in the rectal gland intact or modified, before it is released together with pheromones during sexual advertisement ${ }^{4-7}$. Lure consumption may also improve male competitiveness and mating success by increasing energy metabolism ${ }^{8}$ and allowing lure-fed males to attract females at an earlier time ${ }^{9}$, and can be used in sterile insect technique management programmes to accelerate sexual maturation $^{10}$. The effects of lure consumption by males varies between species ${ }^{11}$ and male lure ${ }^{12}$. The strong attraction of male fruit flies to lures has allowed these compounds to be used for fruit fly population monitoring and control. Traps containing male lures are routinely used to estimate population sizes, to demonstrate pest-free status, or to detect incursions of invasive species ${ }^{13,14}$. Male lures are also used extensively in the male annihilation technique in which a lure is combined with a toxicant to kill large numbers of male fruit flies such that female fertility is reduced ${ }^{15}$. Lures with improved attractiveness to fruit flies enable more effective management and monitoring.

Many dacine fruit flies respond to either of two male lures: methyl eugenol (4-allyl-1,2-dimethoxybenzene) or cuelure (4-(4-acetoxyphenyl)-2-butanone) (Fig. 1) ${ }^{16}$. Cuelure is the acetyl ester of raspberry ketone (4-(4-hyd roxyphenyl)-2-butanone) (Fig. 1), a far more common compound in nature that is also attractive, but less so than cuelure probably due to its lower volatility and release rate ${ }^{17,18}$. Bactrocera, Zeugodacus, and Dacus species are typically categorised as being methyl eugenol responsive, cuelure/raspberry ketone responsive, or non-responsive ${ }^{19,20}$. However, around $50 \%$ of species do not respond to either methyl eugenol or cuelure, or have never been trapped using these lures ${ }^{16,20,21}$.

${ }^{1}$ Department of Molecular Sciences, Macquarie University, North Ryde, NSW, 2109, Australia. ${ }^{2}$ Department of Agriculture and Fisheries, PO Box 267, Brisbane, Qld, 4000, Australia. ${ }^{3}$ Department of Biological Sciences, Macquarie University, North Ryde, NSW, 2109, Australia. *email: ian.jamie@mq.edu.au 
<smiles>C=CCc1ccc(OC)c(OC)c1</smiles>

Methyl Eugenol<smiles>CC(=O)CCc1ccc(O)cc1</smiles>

Raspberry Ketone<smiles>CC(=O)CCc1ccc(OC(C)=O)cc1</smiles>

Cuelure<smiles>COc1cc(CCC(C)=O)ccc1O</smiles>

Zingerone

Figure 1. Chemical structures of the male chemical lures methyl eugenol, raspberry ketone, cuelure, and zingerone.

Zingerone (4-(4-hydroxy-3-methoxyphenyl)-2-butanone) (Fig. 1) is a compound that illustrates the complexity of fruit fly lure attraction. The flowers of two Bulbophyllum orchids (Bu. patens King and Bu. baileyi F. Muell.) have been observed to attract males of some fruit flies, including the methyl eugenol responsive $B$. carambolae Drew \& Hancock and B. dorsalis (Hendel), and the cuelure/raspberry ketone responsive B. albistrigata (de Meijere), Z. caudatus (Fabricius), Z. cucurbitae (Coquillett), and Z. tau (Walker) ${ }^{22,23}$. Laboratory and field trials showed that zingerone was the active component in the flower volatiles ${ }^{22,23}$. A mixture of methyl eugenol responsive and cuelure/raspberry ketone responsive fruit flies were attracted by zingerone, which makes zingerone unique among male lures as no species is attracted to both methyl eugenol and cuelure/raspberry ketone ${ }^{19}$.

While zingerone can attract both methyl eugenol responsive and cuelure/raspberry ketone responsive species, zingerone is a much weaker lure for $B$. dorsalis and $Z$. cucurbitae than methyl eugenol or cuelure, respectively ${ }^{11,22,23}$. Field trials with zingerone and a small number of zingerone analogues have revealed that some other fruit fly species are strongly attracted to zingerone, including Jarvis's fruit fly, B. jarvisi (Tryon) ${ }^{24-28}$, which has an olfactory threshold to zingerone of $179 \mathrm{ng}$ (effective median dose, $\left.\mathrm{ED}_{50}\right)^{29}$. Previously considered to be a non-responsive species or only weakly attracted to cuelure ${ }^{16,24,27}$, the discovery of the strong attraction of $B$. jarvisi to zingerone represents the first effective lure for this species. Bactrocera jarvisi is a moderate pest species, with mangoes being the most susceptible commercial $\mathrm{crop}^{30,31}$, and is distributed through northern Australia, from Broome to eastern Arnhem Land and along the east coast of Australia from Cape York to Sydney ${ }^{16}$. While zingerone is structurally similar to both methyl eugenol and raspberry ketone (Fig. 1), the particular structural features of zingerone that are responsible for attraction of B. jarvisi and other responsive fruit flies are poorly understood.

Experiments using lure analogues can provide instructive insights into the structural, chemical, and physical properties that are required for attraction, and can help to identify compounds that are more attractive than existing lures. Attraction to lures is mediated by protein receptors in the antennae, or other olfactory organs, and since the structure of these receptors has not yet been elucidated in B. jarvisi, the testing of analogues provides valuable information regarding the lure binding site in these receptors.

Many analogues of methyl eugenol and cuelure have been evaluated for their attraction of $B$. dorsalis and $Z$. cucurbitae, respectively. Patterns in the attraction of analogues were used to elucidate the key structural features of methyl eugenol and cuelure and sites of modification in laboratory bioassays ${ }^{32-35}$. Research into methyl eugenol analogues has also been concerned with developing analogues that eliminate or minimise the suspected carcinogenicity potential of methyl eugenol ${ }^{36}$, with side chain fluorinated analogues being the most effective compounds tested $^{37-40}$. While chemical structure has been found to be more important for attraction than vapour pressure in some studies ${ }^{18,35}$, vapour pressure is considered important for effective lure attraction ${ }^{41}$, and efforts to increase the vapour pressure of cuelure have focused on developing analogues with phenolic ester, fluorinated, and silyl ether modifications ${ }^{18,42,43}$.

Unlike methyl eugenol and cuelure, few analogues of zingerone have been evaluated in the field for attraction of fruit flies. In the present study, zingerone analogues were synthesised and evaluated in the field to elucidate the functional groups that mediate attraction of $B$. jarvisi and to probe for sites of potential structural modification of zingerone. Bactrocera jarvisi was chosen as a model species due to its strong response to zingerone, but the insights of this study also provide important guidance for the development of effective lures for other species. Additionally, some analogues that were expected to have higher vapour pressures were included, including some fluorinated compounds. To evaluate the effect of structural modifications on vapour pressure, differential 
<smiles>CCOc1cc(CCC(C)=O)ccc1OCC(=O)CCc1ccc(OC(=O)CC(C)=O)c(OC)c1</smiles><smiles>COc1ccc(CCC(C)=O)cc1O</smiles><smiles>CC(=O)CCc1ccc2c(c1)OCO2</smiles><smiles>CC(=O)CCc1ccc2c(c1)OC(F)(F)O2</smiles><smiles>CCOc1cc(CCC(C)=O)ccc1N</smiles><smiles>COc1cc(CCC(C)=O)ccc1N(C)C</smiles><smiles>COc1cc(CCC(C)=O)ccc1NC=O</smiles><smiles>COc1cc(CCC(C)=O)ccc1N(C)C=O</smiles><smiles>COc1cc(CCC(C)=O)ccc1NC(C)=O</smiles><smiles>CC(=O)CCc1ccc(N(C)C(C)=O)c(OC[I+])c1</smiles><smiles>COc1cc(CCC(C)=O)ccc1NC(=O)C(F)(F)F</smiles><smiles>COc1cc(CCC(C)=O)ccc1N(C)C(=O)C(F)(F)F</smiles><smiles>COc1cc(O)ccc1CCC(C)=O</smiles><smiles>CC(=O)CCc1ccc(O)c(O)c1</smiles><smiles>CC(=O)CCc1ccc(O)c([N+](=O)[O-])c1</smiles><smiles>CC(=O)CCc1ccc(OC=O)c(OC(C)=O)c1</smiles><smiles>CC(=O)CCc1ccc(O)c(OC(F)(F)F)c1</smiles><smiles>CCOc1cc(CCCC(C)=O)ccc1O</smiles>

25<smiles>CCCOc1cc(CCC(C)=O)ccc1O</smiles>

26<smiles>[Z7]C(C)Oc1cc(CCC(C)=O)ccc1O</smiles><smiles>CC(=O)CCc1ccc(O)c(OC(C)(C)C)c1</smiles><smiles>COc1cc(CC(C)=O)ccc1O</smiles><smiles>COc1cc(CCC(C)O)ccc1O</smiles><smiles>CC(=O)OCc1ccc(O)c(O[13CH3])c1</smiles><smiles>CC(=O)/C=C/c1ccc(O)c(OCCCO)c1</smiles><smiles>COc1cc(CCC=O)ccc1O</smiles><smiles>CCC(=O)CCc1ccc(O)c(O[Al])c1</smiles><smiles>CC(C)COc1cc(CCC(=O)C(C)C)ccc1O</smiles><smiles>CC(C)(C)C(=O)CCc1ccc(O)c(OCC(=O)c2ccccc2)c1</smiles><smiles>[B]Oc1cc(CC(C)C(C)=O)ccc1O</smiles><smiles>CC(=O)CC(C)c1ccc(O)c(O[13CH3])c1</smiles><smiles>CC(=O)CCc1ccc(OC(C)=O)cc1</smiles>

Figure 2. Chemical structures of the compounds investigated: zingerone (1), zingerone analogues 2-38, and cuelure (39).

scanning calorimetry (DSC) was used to measure the vapour pressure of zingerone and a subset of zingerone analogues that were expected to have higher vapour pressures and hence higher release rates.

\section{Results}

Field trials. The zingerone analogues 2-38 together with zingerone (1) and cuelure (39) (Fig. 2) were tested over three periods during January and February across 2017-2019. The amount of compound used in each trap $(300 \mathrm{mg})$ was between the minimum amount required for short range attraction ${ }^{29}$ and the amount used in longer term field studies ${ }^{24,26,27}$. The blank control traps did not capture any flies. Bactrocera jarvisi represented 


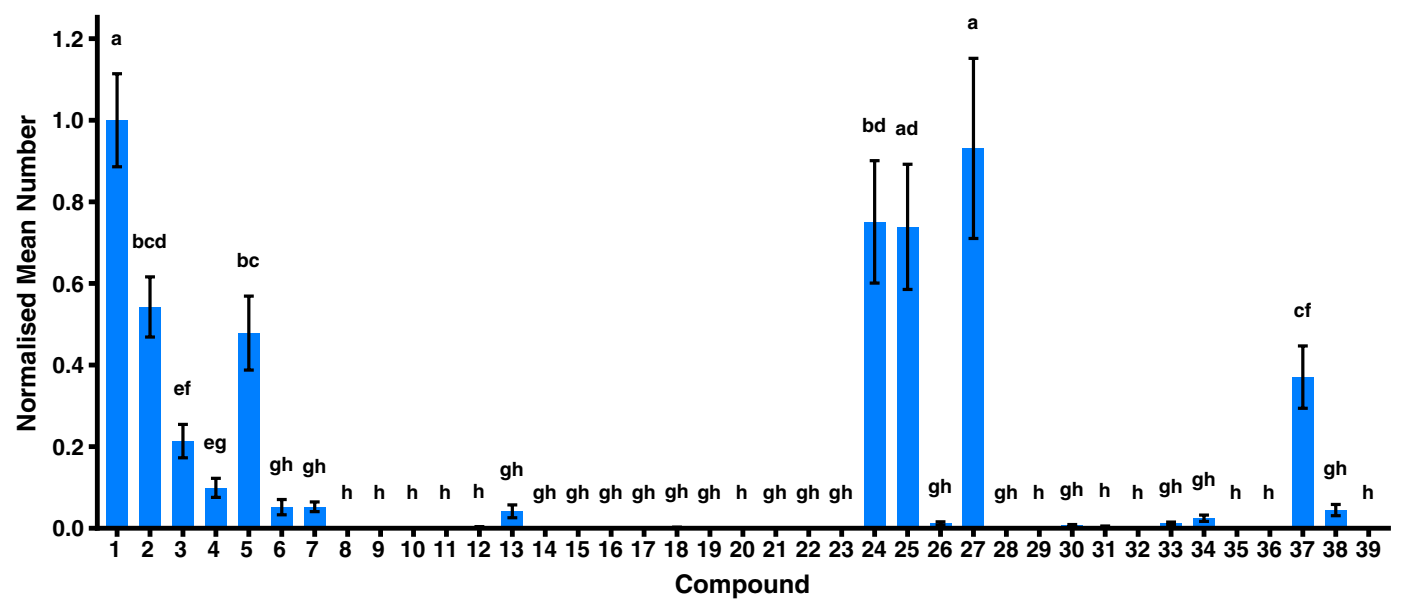

Figure 3. Number of B. jarvisi caught by each compound normalised to zingerone (1) (mean $\pm \mathrm{SE}$ ) of the respective year for the zingerone analogues 2-38 and cuelure (39). Means with a common letter are not significantly different $(p>0.05)$. Statistical analysis was performed on square root transformed values.

99.0-99.9\% of flies collected in zingerone or zingerone analogue traps. Other species collected at zingerone or zingerone analogue traps were predominately B. tryoni (Froggatt) with smaller numbers of $B$. neohumeralis (Hardy) as well as two specimens of B. breviaculeus (Hardy) and a single D. secamoneae Drew. A similar proportion of $B$. tryoni in zingerone traps was found by previous studies ${ }^{24,27}$. Cuelure (39) traps caught between seven and nine species each season, primarily $B$. tryoni (68.3-83.4\%), with smaller numbers of B. neohumeralis, B. breviaculeus, B. aeroginosa (Drew \& Hancock), B. alyxiae (May), B. bryoniae (Tryon), B. quadrata (May), B. peninsularis (Drew \& Hancock), B. rufofuscula (Drew \& Hancock), B. silvicola (May), Z. choristus (May), and Z. cucumis (French) (a single female), which have all been previously recorded in Australia at cuelure traps ${ }^{16}$. Three male B. jarvisi were caught by cuelure (39) traps during the 2019 field trial.

To allow for comparison across three years of trials, the number of B. jarvisi caught per trap per day was normalised to the value for zingerone (1) in the respective year. This controls for different abundances of $B$. jarvisi from year to year. The normalised field catches for the 37 zingerone analogues and cuelure (39) are presented in Fig. 3 and the absolute number of $B$. jarvisi caught per trap per day in each year is shown in Supplementary Table S1. Zingerone (1), the phenolic esters 2-3 and 5, the methoxy derivatives 24-25 and 27, and the 3-methyl2-butanone analogue 37 were the most attractive compounds (Fig. 3). While the phenolic esters (2-7) were less attractive than zingerone, all of the phenolic esters were attractive. Despite having the same ester chain length as 4 , the 3,3,3- trifluoropropionyl ester 5 was significantly more attractive than $\mathbf{4}(p<0.001)$ and was as attractive as the smaller formyl ester 2 . Several nitrogen-containing analogues were tested including an aniline 12, an $N, N$-dimethylaniline 13, and the amides (14-19); of which, only the $N, N$-dimethylaniline 13 was weakly attractive. The attraction of the methoxy derivatives (20-28) was clearly divided between unattractive and highly attractive compounds. The only attractive methoxy derivatives were the trifluoromethoxy 24 , ethoxy $\mathbf{2 5}$, and isopropoxy 27 analogues. Methylation of the terminal end of the butanone chain resulted in a rapid reduction in attraction with the 3-pentanone analogue 34 being weakly attractive and the 2-methyl-3-pentanone 35 and 2,2-dimethyl-3-pentanone 36 analogues being unattractive. Methylation on the other side of the ketone, the benzene ring side of the ketone (37), was significantly more tolerated than terminal methylation as in the 3 -pentanone 34 analogue $(p<0.001)$. There was also a difference in the attraction of the two analogues that had methyl groups added between the ketone and benzene ring, with the 3-methyl-2-butanone analogue 37 being significantly more attractive than the 4-methyl-2-butanone analogue $38(p<0.001)$.

Compound retention and loss. The wicks from field trials were collected and analysed to determine the amount of each compound remaining and if any chemical change had occurred, such as hydrolysis. Figure 4 shows the relative amount of each compound remaining from the three field trials.

After the field trials most wicks still had $80-100 \%$ of the initial amount of compound remaining. The diformyl ester 23, however, had completely hydrolysed to the diphenol analogue $\mathbf{2 1}$ by the end of the field trial. The benzyl acetate analogue 31 had only $20 \%$ of the initial amount of material remaining on the wicks together with approximately $5 \%$ of the hydrolysis product, 4 -hydroxy-3-methoxybenzyl alcohol. The formyl ester 2 was the only other ester that experienced significant hydrolysis, with the amount of the hydrolysis product, zingerone, increasing from an initial amount of $5 \%$ to approximately $12 \%$ at the end of the field trial. The difluoromethylenedioxy analogue 11 experienced a large loss of compound during the field trials with only $16 \%$ remaining on average across the three sites. The propanone $\mathbf{2 9}$ and propionaldehyde $\mathbf{3 3}$ analogues also had a greater loss of material than most of the other compounds. Except for the hydrolysis products of the esters 2, 23, and 31, no other chemical transformation products were detected by GC-FID. While evaporation and hydrolysis were the main expected routes of compound loss, loss of the compounds may have also occurred through consumption of the compounds by flies ${ }^{32,33,35}$ and through degradation into products not detected by this method. However, the high recovery of most compounds indicates that any loss through consumption or degradation was minimal. Additionally, the greater loss of some compounds could generally be attributed to hydrolysis or relatively high vapour pressure. 


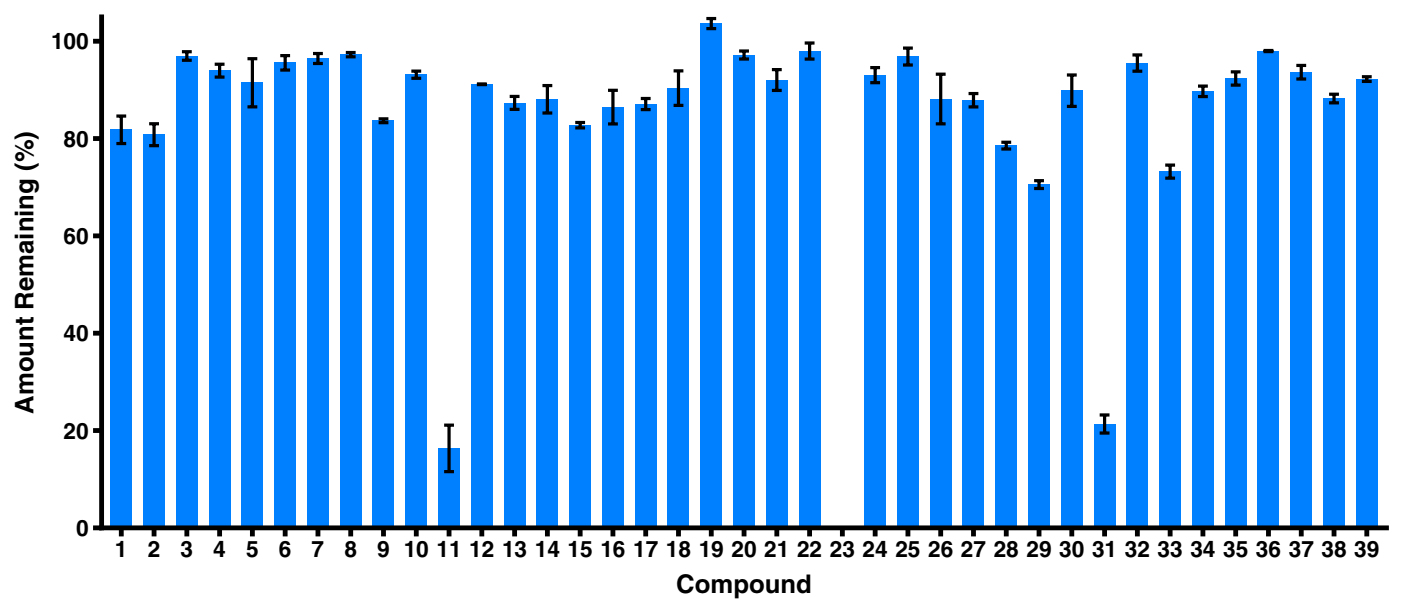

Figure 4. Relative amount of each compound (mean $\pm \mathrm{SE}$ ) remaining on the wicks at the end of field trials.

\begin{tabular}{|l|l|l|l|}
\hline Compound & $\begin{array}{l}\text { Vapour Pressure } \\
\text { at 298.15 K } \mathbf{( P a})\end{array}$ & $\begin{array}{l}\text { Volatility at } \\
\mathbf{2 9 8 . 1 5} \mathbf{~ K}\left(\mathbf{m g ~ m}^{-3}\right)\end{array}$ & $\begin{array}{l}\text { Relative Vapour } \\
\text { Pressure }\end{array}$ \\
\hline 1 & 0.011 & 0.87 & 1.0 \\
\hline 2 & 0.0054 & 0.49 & 0.49 \\
\hline 3 & 0.0057 & 0.54 & 0.51 \\
\hline 8 & 0.028 & 2.4 & 2.5 \\
\hline 10 & 0.10 & 7.8 & 9.0 \\
\hline 11 & 0.73 & 67 & 66 \\
\hline 24 & 0.078 & 7.8 & 7.0 \\
\hline
\end{tabular}

Table 1. Vapour pressure, volatility, and relative vapour pressure extrapolated to $298.15 \mathrm{~K}$ using the Antoine Equation for compounds 1-3, 8, 10-11, and 24 .

Vapour pressure. The boiling points of some of the analogues expected to have greater vapour pressures $(2-3,8,10-11$, and 24), as well as zingerone, were measured using DSC under different applied reduced pressures to produce a set of temperature-pressure data for each compound, which are shown in Supplementary Table S2. These temperature-pressure data were used to obtain the Antoine Equation parameters $A, B$, and $C$, which are presented in Supplementary Table S3 together with the validity range of the fitted curve. Extrapolating the fitted Antoine Equations, the vapour pressure and volatility of each compound was determined at $298.15 \mathrm{~K}\left(25^{\circ} \mathrm{C}\right)$ and is summarised in Table 1 . The two phenolic esters examined, the formyl ester 2 and acetyl ester 3, had a vapour pressure approximately half that of zingerone (1). Methylation of the phenol of zingerone to give methylzingerone (8) resulted in a 2.5-fold increase in vapour pressure compared to zingerone. The methylenedioxy analogues (10 and 11) had much higher vapour pressures than zingerone with the vapour pressure of the fluorinated methylenedioxy analogue 11 being 7 -fold greater than the non-fluorinated methylenedioxy analogue $\mathbf{1 0}$. The trifluoromethoxy analogue $\mathbf{2 4}$ also had a 7 -fold greater vapour pressure than the non-fluorinated zingerone.

\section{Discussion}

This study identifies elements of the zingerone structure that are critical for attraction of $B$. jarvisi and elucidates some steric and electronic requirements of the receptor binding site. Many of the attractive compounds are phenolic esters (2-7) of zingerone. It was expected that the esters would be attractive because esters of raspberry ketone are attractive to raspberry ketone responsive flies with some being even more attractive than raspberry ketone, such as cuelure and melolure (4-(4-formoxyphenyl)-2-butanone $)^{41}$. Unlike the esters of raspberry ketone, the esters of zingerone are not more attractive than the parent compound. This opposite trend could be due to the lower vapour pressure of the zingerone esters compared to zingerone (Table 1). Conversely, raspberry ketone esters have a higher vapour pressure than raspberry ketone ${ }^{18}$, which should increase the release rate and atmospheric concentration of the esters emitted from traps, and thereby attraction ${ }^{41}$. For the non-fluorinated phenolic esters, the order of the attractiveness to B. jarvisi $(\mathbf{6} \leq \mathbf{4}<\mathbf{3}<\mathbf{2})$ is opposite to the size of the ester group (formyl $\mathbf{2}<$ acetyl $\mathbf{3}<$ propionyl $\mathbf{4}<$ isobutyryl 6) (Fig. 5). An inverse relationship has been proposed for raspberry ketone and its esters ${ }^{41}$. Vapour pressure may be partially responsible for this relationship as a larger ester group will tend to decrease the vapour pressure of the compound. While melolure, which has a small formyl group, is more attractive than cuelure to some species, it is not universally more attractive to all cuelure responsive species than cuelure, which has a larger acetyl group ${ }^{24,42}$. The ability of the esters to fit in the binding site of the receptor may also explain this relationship, with smaller esters being more easily accommodated in the binding site. However, the attractiveness of the two fluorinated phenolic esters is contradictory. The 3,3,3-trifluoropropionyl ester $\mathbf{5}$, which was as attractive as the formyl ester $\mathbf{2}$, suggests that if the ester is not hydrolysed before reaching the 


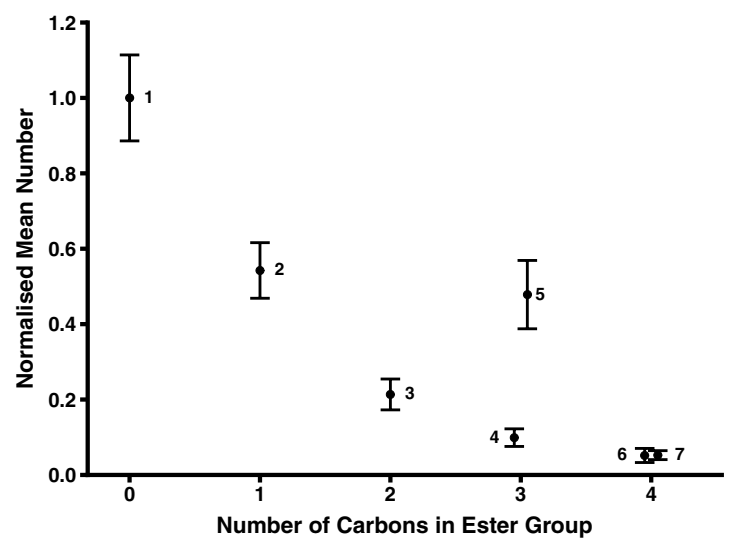

Figure 5. Number of B. jarvisi caught by zingerone (1) and the phenolic esters (2-7) normalised to zingerone (mean \pm SE) against the number of carbons in the ester functional group. Numbers beside data points indicate the compound number.

receptor, the binding site can accommodate larger ester groups. This supports the vapour pressure explanation as the presence of fluorine could have significantly increased the vapour pressure of $\mathbf{5}$. Despite also being fluorinated, the hexafluoroisobutyryl ester 7 was only as attractive as its non-fluorinated equivalent, the isobutyryl ester 6, which may suggest that the vapour pressure of $\mathbf{7}$ is not appreciably greater than $\mathbf{6}$.

Other modifications to the phenol of zingerone, including alkylation and replacement of the $\mathrm{OH}$ group with the isosteric $\mathrm{NH}_{2}$, resulted in much weaker attraction than with the phenolic esters. Simple methylation, as in methylzingerone (8), clearly demonstrates the loss of attraction with alkylation. Isozingerone (9) and the methylenedioxy analogues (10 and $\mathbf{1 1}$ ) are complicated by additional modification of the meta methoxy group as well as alkylation of the phenol. Alkylation removes the ability of the compounds to interact through hydrogen bond donation. The lack of attraction of these ether compounds could indicate that zingerone and similar phenols are acting as hydrogen bond donors. However, the phenolic esters cannot act as hydrogen bond donors yet are still attractive compounds. Hydrolysis of the phenolic esters to zingerone by esterases present in the sensilla lymph ${ }^{44,45}$ prior to receptor detection could explain the difference in attraction between the phenolic esters and the ethers. The methylenedioxy analogues (10 and 11) also show that despite possessing relatively high vapour pressures (Table 1) and a high rate of evaporation for 11 (Fig. 4), the chemical structure tends to be the dominant factor in determining attractiveness. The anilines (12 and 13) and amides (14-19), which are isosteric with zingerone (1), methylzingerone (8), and the phenolic esters (2-7) respectively, were unattractive except for the weakly attractive $\mathrm{N}, \mathrm{N}$-dimethylaniline 13. This may have been due to the weaker hydrogen bonding properties or suboptimal structural conformations compared to zingerone and the phenolic esters. While methylation of zingerone to methylzingerone (8) eliminated attraction, methylation of the aniline $\mathbf{1 2}$ to $\mathrm{N}, \mathrm{N}$-dimethylaniline 13 increased attraction.

The strength of attraction of $B$. jarvisi to the analogues was very sensitive to changes to the methoxy group of zingerone. Moving the methoxy group ortho to the butanone chain, as in 20, eliminated attraction, which indicates that the methoxy group is involved in some critical interaction with the receptor. The very weak attractiveness or unattractiveness of raspberry ketone and analogues, such as cuelure $(39)^{26,27,29}$, which lack the meta methoxy group, further demonstrate the importance of a methoxy group in that position for $B$. jarvisi attraction. Replacing the methoxy group with functional groups other than alkoxys, such as phenol (21), nitro (22), and formoxy (23), also yielded unattractive analogues. The trifluoromethoxy analogue $\mathbf{2 4}$ is the most structurally similar to zingerone with fluorine often considered to approximate the size of hydrogen ${ }^{46}$. Despite this high structural similarity and the addition of fluorine, which increased the vapour pressure compared to zingerone (Table 1), the replacement of the methoxy group with a trifluoromethoxy group had an overall negative effect on attraction. The presence of the trifluoromethoxy group alters the electronic properties of the compound and the inductive electron-withdrawing effect of the trifluoromethoxy group might be responsible for reduced attractiveness. Analogues with larger alkoxy groups were investigated and provided some insight into the steric constraints of the receptor binding site. The ethoxy analogue $\mathbf{2 5}$ was as attractive as zingerone (1) but an increase in the alkoxy chain length to a propoxy group (26) virtually eliminated attraction with $\mathbf{2 6}$ catching only approximately $1 \%$ of the number of $B$. jarvisi caught by zingerone. The isopropoxy analogue 27 was also a three-carbon alkoxy group but is branched as opposed to the linear chain of 26, and like the ethoxy analogue 25, the isopropoxy analogue 27 was as attractive as zingerone. Increasing the bulkiness of the alkoxy group to a tert-butoxy group (28) resulted in an unattractive analogue. The field attraction of $\mathbf{2 5 - 2 8}$ suggests that the receptor binding site can accommodate compounds with an alkoxy group of 1-2 carbons in length and with some bulkiness but less than that of a tert-butoxy.

The lack of attraction of $B$. jarvisi to the butanone derivatives 29-32 highlights the importance of the carbonyl group for attraction. The carbonyl group has been moved closer to the benzene ring in the propanone analogue 29 and reduced to an alcohol in zingerol (30), which demonstrate that the presence and position of the carbonyl group is critical. Chemical analysis of the wicks after field trials indicated that there was some hydrolysis of the 
benzyl acetate analogue 31, which may be the reason for its lack of attraction of B. jarvisi. The hydrolysis product of 31, 4-hydroxy-3-methoxybenzyl alcohol, does not possess the carbonyl group necessary for effective attraction. The lack of $B$. jarvisi attraction by dehydrozingerone (32) may be due to the alkene preventing the compound from assuming a particular conformation that allows the carbonyl group to correctly interact with the receptor binding site.

The effect of increasing the steric bulk around the butanone chain on attraction was explored by adding methyl groups to the butanone chain. Placing an additional methyl group on the terminal end of the butanone chain (34) substantially reduced the attractiveness to B. jarvisi, which suggests that the receptor binding site cannot accommodate larger functional groups at the end of the butanone chain. Indeed, increasing the bulkiness of the end of the butanone chain further with 2-methyl-3-pentanone (35) and 2,2-dimethyl-3-pentanone (36) chains completely eliminated attraction. With a limited ability to accommodate bulkiness, it is interesting that the propionaldehyde analogue 33 is also unattractive to B. jarvisi. This may be due to this analogue possessing an aldehyde rather than a ketone, which confers greater reactivity to 33, or the terminal methyl group of the butanone chain may be critical for receptor recognition. Since an additional methyl group was not tolerated on the terminal side of the ketone, it was expected that the 3-methyl-2-butanone analogue 37 would be unattractive, yet 37 was moderately attractive while the 4-methyl-2-butanone analogue 38 was unattractive. This suggests that the receptor binding site can accommodate somewhat more steric bulk on the benzene ring side of the ketone than the terminal methyl side. The unattractiveness of the 4-methyl-2-butanone analogue $\mathbf{3 8}$ may be due to an inability to sterically accommodate the additional methyl group or it interferes with recognition of the benzene ring.

In summary, we report on the response of B. jarvisi to a series of analogues of zingerone using field trials. Field trials of the compounds found that the most attractive analogues were the formyl $\mathbf{2}$ and 3,3,3-trifluoropropionyl 5 phenolic esters; the trifluoromethoxy 24 , ethoxy 25 , and isopropoxy 27 alkoxy analogues; and the 3-methyl2 -butanone analogue 37 , though none were more attractive than zingerone. For zingerone and the analogues with measured vapour pressures, there was little correlation between vapour pressure and field attractiveness to B. jarvisi. While all of the phenolic esters tested were somewhat attractive, the response decreased with increasing size of the ester, except for the fluorinated ester 3,3,3-trifluoropropionyl 5, which was as attractive as the formyl ester 2 . The attraction of $B$. jarvisi to the alkoxy analogues suggests that the receptor can only accommodate alkoxy groups of 1-2 carbons in length and the bulkiness of an isopropoxy but not that of a tert-butoxy. Greater steric bulk around the butanone chain generally resulted in unattractive analogues with only methylation on the benzene ring side of the ketone being moderately attractive. These results demonstrate that the carbonyl group, phenol, and methoxy group are key sites for the attraction of $B$. jarvisi and identify some constraints on the range of structural modifications that can be made to zingerone without compromising attraction.

\section{Methods and Materials}

Reagents and synthesis of zingerone analogues. The compounds used in this study are presented in Fig. 2. Zingerone (1) ( $\geq 96 \%$ purity), the propanone analogue 29 (96\%), dehydrozingerone (32) ( $\geq 98.5 \%)$, and cuelure (39) ( $\geq 96 \%$ ) were purchased from Sigma-Aldrich and used without further purification. The esters 2 , 5 , and 7 were synthesised from zingerone and the appropriate carboxylic acid by the Steglich esterification ${ }^{47}$. The formyl ester 2 sample still contained approximately 5\% zingerone by GC-FID and ${ }^{1} \mathrm{H}-\mathrm{NMR}$ after purification. The esters 3, 4, and 6 were synthesised from zingerone and the appropriate acid anhydride with pyridine as a catalyst ${ }^{48}$. Analogues 8-11, 20, and 24 were synthesised in two steps from the appropriate substituted benzaldehyde by an aldol condensation ${ }^{49}$ and rhodium on alumina catalysed hydrogenation ${ }^{50}$ of the subsequent enone. The benzaldehyde for the synthesis of $\mathbf{1 0}$ (piperonal) was synthesised from piperonyl alcohol using manganese(IV) oxide $^{51}$. The aniline 12 was also synthesised from an aldol condensation of 4-nitro-3-methoxybenzaldehyde and acetone (optimised from Wang, et al. ${ }^{52}$ ) followed by a rhodium on carbon hydrogenation ${ }^{50}$ of the enone and nitro group. The $N, N$-dimethylaniline 13 was synthesised from the aniline 12 by a formaldehyde reductive amination ${ }^{53}$. The formamide 14 was synthesised from 12 using formic acetic anhydride ${ }^{54}$. The acetamide 16 and trifluoroacetamide 18 were synthesised from 12 and the appropriate acid anhydride ${ }^{55}$. The $N$-methylamides 15, 17, and 19 were synthesised by $N$-methylation of the appropriate secondary amide with methyl iodide but after purification still contained approximately $15 \%, 12 \%$, and $5 \%$ impurities, respectively, by GC-FID and ${ }^{1} \mathrm{H}-\mathrm{NMR}^{56}$. The nitrophenol analogue 22 was synthesised by aromatic nitration of raspberry ketone using nitric acid ${ }^{57}$. The diformyl ester 23 was synthesised from 4-(4-benzyloxy-3-hydroxyphenyl)-2-butanone using formic acetic anhydride followed by deprotection with palladium on carbon ${ }^{58}$ and further reaction with formic acetic anhydride ${ }^{54}$. The starting material for 23 was synthesised by benzyl protecting 3,4-dihydroxybenzaldehyde ${ }^{59}$ and reacting this with acetone in an aldol condensation (optimised from Wang, et al. ${ }^{52}$ ) followed by rhodium on carbon hydrogenation ${ }^{50}$. Analogues 21, 25, and 34-36 were synthesised from the appropriate benzyl protected benzaldehyde ${ }^{60}$ by an aldol condensation (optimised from Wang, et al. ${ }^{52}$ for 21, 25, and 34 and modified from Plourde ${ }^{58}$ for 35-36) and rhodium on alumina catalysed hydrogenation ${ }^{50}$ of the enone followed by deprotection using palladium on carbon $^{58}$. Analogues 26 and 27 were synthesised by alkylating 4-(4-benzyloxy-3-hydroxyphenyl)-2-butanone with an appropriate alkyl halide ${ }^{61}$ followed by deprotection using palladium on carbon ${ }^{58}$. The tert-butoxy analogue 28 was synthesised by alkylating 4-(4-benzyloxy-3-hydroxyphenyl)-2-butanone with di-tert-butyl dicarbonate and scandium(III) triflate as a catalyst ${ }^{62}$ followed by deprotection using palladium on carbon ${ }^{58}$. Zingerol (30) was synthesised from the sodium borohydride reduction of zingerone $e^{63}$. The benzyl acetate analogue 31 was synthesised by selective acetylation of 4-hydroxy-3-methoxybenzyl alcohol with acetic acid and potassium fluoride $^{64}$. The propionaldehyde analogue 33 was synthesised in a multiple step procedure starting with the benzyl protection of vanillin ${ }^{60}$ followed by a Horner-Wadsworth-Emmons reaction using triethyl phosphonoacetate ${ }^{65}$ then hydrogenation with rhodium on alumina ${ }^{50}$, reduction of the ester with DIBAL ${ }^{66}$, and finally deprotection with palladium on carbon ${ }^{58}$. The 3-methyl-2-butanone analogue 37 was synthesised by benzyl protecting zingerone ${ }^{60}$ followed by $\alpha$-methylenation using paraformaldehyde and piperidine ${ }^{67}$ then concurrent deprotection 
and hydrogenation using palladium on carbon $^{58}$. The 4-methyl-2-butanone analogue 38 was synthesised from benzyl protected dehydrozingerone $(\mathbf{3 2})^{52,60}$ followed by conjugate addition with methyllithium and copper(I) iodide $^{68}$ then deprotection with palladium on carbon ${ }^{58}$. Detailed reaction procedures and spectra are presented in the supplementary information.

Field trials. Field trials were undertaken at Walkamin Research Facility $\left(17.13797^{\circ} \mathrm{S}, 145.41508^{\circ} \mathrm{E}\right)$, Malone Road $\left(17.00298^{\circ} \mathrm{S}, 145.46742^{\circ} \mathrm{E}\right)$, and Mareeba Research Facility $\left(17.00724^{\circ} \mathrm{S}, 145.42984^{\circ} \mathrm{E}\right)$, on the Atherton Tableland region of north Queensland between 10 January 2017 and 27 January 2017, 24 January 2018 and 3 February 2018, and 29 January 2019 and 17 February 2019. Compounds ( $300 \pm 3 \mathrm{mg}$ ) were dissolved in acetone (or methanol for 32) and applied to cotton dental wicks. Untreated wicks were used as blank controls (negative control). Once the solvent had evaporated, the wicks were placed in the centre of McPhail traps (BioTrap V1 (2017 field trial), BioTrap V2 (2018 field trial), and BioTrap V2 X (2019 field trial); BioTrap Australia Pty Ltd.) with a single dichlorvos cube (2,2-dichlorovinyl dimethyl phosphate, BioTrap Australia Pty Ltd.). Replicate sets of traps, comprising the compounds and blank control, were hung in shade under trees (Walkamin Research Facility: fruiting mango trees (2017), non-fruiting mango trees (2018), and a mixture of non-fruiting mango and peach trees (2019); Malone Road: fruiting mango trees (2017), non-fruiting mango trees (2018-2019); Mareeba Research Facility: non-crop trees (2017-2019)) approximately $1.5 \mathrm{~m}$ above the ground with a minimum of $10 \mathrm{~m}$ separation between traps. The traps were cleared daily and moved into the next trap position such that each trap only spent one day in each position. Flies were examined under a stereomicroscope and identified by referencing Drew ${ }^{16}$.

Field trial data were analysed using the software $\mathrm{R}^{69}$ and $\mathrm{RStudio}^{70}$ with the emmeans package $\mathrm{e}^{71}$ and plotted with the ggplot 2 package ${ }^{72}$. For analysis, a linear model was used in which the daily B. jarvisi catch was the response variable. The daily $B$. jarvisi catch values were $\sqrt{x+0.5}$ transformed before statistical analysis. The predictors in the model were compound and site and the interaction between these two variables was included. A pairwise comparison between each compound was performed with Tukey's Honest Significant Difference test for multiple comparisons. The statistical analysis was repeated with the transformed daily B. jarvisi catch values normalised to the transformed value of zingerone (1) in the respective year to account for variations in the abundance of $B$. jarvisi year-to-year. Graphical analysis of the Pearson residuals was used to assess model assumptions.

Compound retention and loss. At the conclusion of field trials, the wicks were immediately removed from the traps and stored in sealed vials for later analysis. Wicks were extracted with ethyl acetate for two hours at room temperature and tridecane was added to each wick as an internal standard. The extracts were diluted with ethyl acetate to an appropriate concentration for analysis by GC-FID. Quantification of the extracts was performed using a Shimadzu GC-17A gas chromatograph with flame ionisation detection and a Shimadzu AOC$20 \mathrm{i}$ autosampler. A Restek Rxi-5Sil MS $30 \mathrm{~m}$ column was employed, with the injector at $270^{\circ} \mathrm{C}$, the initial oven temperature at $100^{\circ} \mathrm{C}$ for $1 \mathrm{~min}$, then ramped at $15^{\circ} \mathrm{C} \mathrm{m^{-1 }}$ to a final temperature of $250^{\circ} \mathrm{C}$ and held for $1 \mathrm{~min}$. Extracts were analysed in triplicate and the quantity of compound reported relative to the initial $300 \mathrm{mg}$ amount.

Compound retention and loss data were analysed using the software $\mathrm{R}^{69}$ and RStudio ${ }^{70}$ with the ggplot $2^{72}$ package. The relative quantity of material remaining on each wick was averaged across the three sites and three field trials (for zingerone (1) and cuelure (39)) to give a mean value for each compound. The value for zingerone at the Walkamin Research Facility site in the 2019 field trial was excluded as an outlier.

Vapour pressure. Vapour pressure measurements were conducted on a TA Instruments 2010 DSC equipped with a standard DSC cell. Vacuum was achieved with a Vacuubrand MD4 diaphragm vacuum pump between 15 $\mathrm{kPa}$ and $0.5 \mathrm{kPa}$ and an Edwards E2M-1.5 high vacuum pump between $0.5 \mathrm{kPa}$ and $0.15 \mathrm{kPa}$. The pressure was regulated by a needle valve to balance inflow and outflow with the absolute pressure measured by an Edwards Active Pirani Gauge APG-L-NW16.

Calibration of the DSC was performed in accordance with ASTM E967-08. Temperature calibration was conducted with indium and lead. After temperature calibration of the DSC the pressure gauge was calibrated by measuring the boiling point of 1 -octanol under different reduced pressures between atmospheric and $0.14 \mathrm{kPa}$ and comparing the measured pressure to literature pressure-boiling data for 1 -octanol ${ }^{73}$.

Samples of 8-14 mg of 1-3, 8, 10-11, and 24 were weighed on a micro-analytical balance with a precision of $\pm 0.01 \mathrm{mg}$ and placed in hermetic aluminium pans (TA Instruments) and sealed hermetically with hermetic pinholes lids (TA Instruments). Samples of the formyl ester 2 were of lower purity and contained approximately $5 \%$ zingerone. For pressures between atmospheric and $7 \mathrm{kPa}$, pinholes with a diameter of $75 \mu \mathrm{m}$ were used. Use of pressures below $7 \mathrm{kPa}$ required pinholes larger than $75 \mu \mathrm{m}$, which were prepared by manually punching the lids with a needle and the pinhole size was determined by microscopy. For pressures between $7 \mathrm{kPa}$ and $1 \mathrm{kPa}$, pinhole diameters ranging from approximately $290 \mu \mathrm{m}$ to $340 \mu \mathrm{m}$ were used. Below $1 \mathrm{kPa}$, use of larger pinhole diameters ranging from approximately $460 \mu \mathrm{m}$ to $540 \mu \mathrm{m}$ was necessary. Due to reduced thermal contact between the pans and the sample and reference platforms of the DSC at reduced pressures, thermally conductive paste was applied to the pans and platforms for pressures $<7 \mathrm{kPa}$.

The operation of the DSC for vapour pressure measurements was performed in accordance with ASTM E1782-14 with a modified pressure range ( $15 \mathrm{kPa}$ to $0.15 \mathrm{kPa})$. After achieving the desired pressure, the sample in the DSC was rapidly heated to approximately $50^{\circ} \mathrm{C}$ below its expected boiling point and allowed to equilibrate. Once equilibrated, heating at $5^{\circ} \mathrm{C} \mathrm{min}^{-1}$ was initiated and maintained until a stable baseline was achieved after the sample boiled. The pressure was measured when the sample began to boil, and the temperature of the extrapolated onset point was determined from the DSC endotherm.

The pressure-boiling point data from the DSC measurements were fitted to the Antoine Eq. (1). 


$$
\log P=A-\frac{B}{T+C}
$$

where $P$ is pressure $(\mathrm{kPa}), T$ is temperature $(\mathrm{K})$, and $A, B$, and $C$ are the Antoine parameters. The parameters were obtained by iterative least squares nonlinear regression with MATLAB R2015a (The MathWorks, Inc.). The vapour pressure and volatility of the compounds at room temperature $(298.15 \mathrm{~K})$ were calculated using the Antoine Equation (Eq. (1)) and Eq. (2), respectively.

$$
\text { Volatility }=\frac{P M}{R T} \times 10^{6}
$$

where volatility is given in $\mathrm{mg} \mathrm{m}^{-3}, P$ is vapour pressure $(\mathrm{kPa}), M$ is molar mass $\left(\mathrm{g} \mathrm{mol}^{-1}\right), R$ is the ideal gas constant $\left(\mathrm{J} \mathrm{K}^{-1} \mathrm{~mol}^{-1}\right)$, and $T$ is temperature (K).

Received: 22 October 2019; Accepted: 28 November 2019;

Published online: 18 December 2019

\section{References}

1. Raghu, S. Functional significance of phytochemical lures to dacine fruit flies (Diptera: Tephritidae): an ecological and evolutionary synthesis. Bull. Entomol. Res. 94, 385-399 (2004).

2. Tan, K. H. \& Nishida, R. Methyl eugenol: its occurrence, distribution, and role in nature, especially in relation to insect behavior and pollination. J. Insect Sci. 12, 1-74 (2012).

3. Shelly, T. Effects of methyl eugenol and raspberry ketone/cue lure on the sexual behavior of Bactrocera species (Diptera: Tephritidae). Appl. Entomol. Zool. 45, 349-361 (2010).

4. Wee, S.-L. \& Tan, K. H. Temporal accumulation of phenylpropanoids in male fruit flies, Bactrocera dorsalis and B. carambolae (Diptera: Tephritidae) following methyl eugenol consumption. Chemoecology 17, 81-85 (2007).

5. Nishida, R. et al. Accumulation of phenylpropanoids in the rectal glands of males of the oriental fruit fly, Dacus dorsalis. Experientia 44, 534-536 (1988).

6. Wee, S.-L., Tan, K. H. \& Nishida, R. Pharmacophagy of methyl eugenol by males enhances sexual selection of Bactrocera carambolae. J. Chem. Ecol. 33, 1272-1282 (2007).

7. Tan, K. H. \& Nishida, R. Incorporation of raspberry ketone in the rectal glands of males of the Queensland fruit fly, Bactrocera tryoni Froggatt (Diptera: Tephritidae). Appl. Entomol. Zool. 30, 494-497 (1995).

8. Kumaran, N., Prentis, P. J., Mangalam, K. P., Schutze, M. K. \& Clarke, A. R. Sexual selection in true fruit flies (Diptera: Tephritidae): transcriptome and experimental evidences for phytochemicals increasing male competitive ability. Mol. Ecol. 23, 4645-4657 (2014).

9. Khoo, C. C. H. \& Tan, K. H. Attraction of both sexes of melon fly, Bactrocera cucurbitae to conspecific males-a comparison after pharmacophagy of cue-lure and a new attractant-zingerone. Entomol. Exp. Appl. 97, 317-320 (2000).

10. Akter, H., Mendez, V., Morelli, R., Pérez, J. \& Taylor, P. W. Raspberry ketone supplement promotes early sexual maturation in male Queensland fruit fly, Bactrocera tryoni (Diptera: Tephritidae). Pest Manage. Sci. 73, 1764-1770 (2017).

11. Shelly, T. E. Zingerone and the mating success and field attraction of male melon flies (Diptera: Tephritidae). J. Asia-Pacif. Entomol. 20, 175-178 (2017).

12. Kumaran, N., Hayes, R. A. \& Clarke, A. R. Cuelure but not zingerone make the sex pheromone of male Bactrocera tryoni (Tephritidae: Diptera) more attractive to females. J. Insect Physiol. 68, 36-43 (2014).

13. Chambers, D. L., Cunningham, R. T., Lichty, R. W. \& Thrailkill, R. B. Pest control by attractants: a case study demonstrating economy, specificity, and environmental acceptability. Bioscience 24, 150-152 (1974).

14. Jessup, A. J. et al. In Area-Wide Control of Insect Pests 685-697 (Springer, 2007).

15. El-Sayed, A. M., Suckling, D. M., Byers, J. A., Jang, E. B. \& Wearing, C. H. Potential of "lure and kill" in long-term pest management and eradication of invasive species. J. Econ. Entomol. 102, 815-835 (2009).

16. Drew, R. A. I. The tropical fruit flies (Diptera: Tephritidae: Dacinae) of the Australasian and Oceanian regions. Mem. Queensl. Mus. 26, 1-521 (1989).

17. Metcalf, R. L. Chemical ecology of Dacinae fruit flies (Diptera: Tephritidae). Ann. Entomol. Soc. Am. 83, 1017-1030 (1990).

18. Park, S. J. et al. Raspberry ketone analogs: vapour pressure measurements and attractiveness to Queensland fruit fly, Bactrocera tryoni (Froggatt) (Diptera: Tephritidae). PLoS One 11, e0155827 (2016).

19. Drew, R. A. I. The responses of fruit fly species (Diptera: Tephritidae) in the South Pacific area to male attractants. J. Aust. Entomol. Soc. 13, 267-270 (1974).

20. Drew, R. A. I. \& Hooper, G. H. S. The responses of fruit fly species (Diptera: Tephritidae) in Australia to various attractants. J. Aust. Entomol. Soc. 20, 201-205 (1981).

21. Stibick, J. N. L. Action Plan: Peach Fruit Fly, Bactrocera zonata (Saunders). (Joint FAO/IAEA Division of Nuclear Techniques in Food and Agriculture. International Atomic Energy Agency, Vienna, 2000).

22. Tan, K. H. \& Nishida, R. Mutual reproductive benefits between a wild orchid, Bulbophyllum patens, and Bactrocera fruit flies via a floral synomone. J. Chem. Ecol. 26, 533-546 (2000).

23. Tan, K. H. \& Nishida, R. Zingerone in the floral synomone of Bulbophyllum baileyi (Orchidaceae) attracts Bactrocera fruit flies during pollination. Biochem. Syst. Ecol. 35, 334-341 (2007).

24. Royer, J. E. Responses of fruit flies (Tephritidae: Dacinae) to novel male attractants in north Queensland, Australia, and improved lures for some pest species. Austral Entomol. 54, 411-426 (2015).

25. Royer, J. E. et al. Responses of fruit flies (Diptera: Tephritidae) to new attractants in Papua New Guinea. Austral Entomol. 57, 40-49 (2018).

26. Fay, H. A. C. In Proceedings of the 8th International Symposium on Fruit Flies of Economic Importance, 26 September-1 October 2010, Valencia, Spain. 270-280 (Editorial Universitat Politécnica de Valéncia).

27. Fay, H. A. C. A highly effective and selective male lure for Bactrocera jarvisi (Tryon) (Diptera: Tephritidae). Aust. J. Entomol. 51, 189-197 (2012).

28. Royer, J. E., Khan, M. \& Mayer, D. G. Methyl-isoeugenol, a highly attractive male lure for the cucurbit flower pest Zeugodacus diversus (Coquillett) (syn. Bactrocera diversa) (Diptera: Tephritidae: Dacinae). J. Econ. Entomol. 111, 1197-1201 (2018).

29. Wee, S.-L., Peek, T. \& Clarke, A. R. The responsiveness of Bactrocera jarvisi (Diptera: Tephritidae) to two naturally occurring phenylbutaonids, zingerone and raspberry ketone. J. Insect Physiol. 109, 41-46 (2018).

30. Allwood, A. J. \& Angeles, T. S. Host records of fruit flies (family Tephritidae) in the Northern Territory. Queensl. J. Agric. Anim. Sci. 36, 105-113 (1979).

31. Smith, E. S. C., Chin, D., Allwood, A. J. \& Collins, S. G. A revised host list of fruit flies (Diptera: Tephritidae) from the Northern Territory of Australia. Queensl. J. Agric. Anim. Sci. 45, 19-28 (1988). 
32. Metcalf, R. L., Metcalf, E. R. \& Mitchell, W. Molecular parameters and olfaction in the oriental fruit fly Dacus dorsalis. Proc. Natl. Acad. Sci. USA 78, 4007-4010 (1981).

33. Metcalf, R. L., Mitchell, W. C. \& Metcalf, E. R. Olfactory receptors in the melon fly Dacus cucurbitae and the oriental fruit fly Dacus dorsalis. Proc. Natl. Acad. Sci. USA 80, 3143-3147 (1983).

34. Metcalf, R. L., Metcalf, E. R. \& Mitchell, W. Benzyl acetates as attractants for the male oriental fruit fly, Dacus dorsalis, and the male melon fly, Dacus cucurbitae. Proc. Natl. Acad. Sci. USA 83, 1549-1553 (1986).

35. Metcalf, R. L., Metcalf, E. R., Mitchell, W. \& Lee, L. W. Evolution of olfactory receptor in oriental fruit fly Dacus dorsalis. Proc. Natl. Acad. Sci. USA 76, 1561-1565 (1979).

36. Miller, E. C. et al. Structure-activity studies of the carcinogenicities in the mouse and rat of some naturally occurring and synthetic alkenylbenzene derivatives related to safrole and estragole. Cancer Res. 43, 1124-1134 (1983).

37. Mitchell, W. C., Metcalf, R. L., Metcalf, E. R. \& Mitchell, S. Candidate substitutes for methyl eugenol as attractants for the area-wide monitoring and control of the oriental fruitfly, Dacus dorsalis Hendel (Diptera: Tephritidae). Environ. Entomol. 14, 176-181 (1985).

38. Liquido, N., Khrimian, A., DeMilo, A. \& McQuate, G. Monofluoro analogues of methyl eugenol: new attractants for males of Bactrocera dorsalis (Hendel) (Dipt., Tephritidae). J. Appl. Entomol. 122, 259-264 (1998).

39. Khrimian, A. et al. Ring-fluorinated analog of methyl eugenol: attractiveness to and metabolism in the oriental fruit fly, Bactrocera dorsalis (Hendel). J. Chem. Ecol. 35, 209-218 (2009).

40. Jang, E. B., Khrimian, A. \& Siderhurst, M. S. Di-and tri-fluorinated analogs of methyl eugenol: attraction to and metabolism in the oriental fruit fly, Bactrocera dorsalis (Hendel). J. Chem. Ecol. 37, 553-564 (2011).

41. Metcalf, R. L. \& Metcalf, E. R. Plant Kairomones in Insect Ecology and Control. 139-142 (Chapman and Hall Ltd., 1992).

42. Casaña-Giner, V. et al. Raspberry ketone formate as an attractant for the melon fly (Diptera: Tephritidae). J. Entomol. Sci. 38, $120-126(2003)$

43. Casaña-Giner, V., Oliver, J. E., Jang, E. B. \& Carvalho, L. Syntheses and behavioral evaluations of fluorinated and silylated analogs of raspberry ketone as attractants for the melon fly, Bactrocera cucurbitae (Coquillett). J. Entomol. Sci. 38, 111-119 (2003).

44. Vogt, R. G. \& Riddiford, L. M. Pheromone binding and inactivation by moth antennae. Nature 293, 161 (1981).

45. Younus, F. et al. Identification of candidate odorant degrading gene/enzyme systems in the antennal transcriptome of Drosophila melanogaster. Insect Biochem. Mol. Biol. 53, 30-43 (2014).

46. Schlosser, M. \& Michel, D. About the "physiological size" of fluorine substituents: comparison of sensorially active compounds with fluorine and methyl substituted analogues. Tetrahedron 52, 99-108 (1996).

47. Neises, B. \& Steglich, W. Simple method for the esterification of carboxylic acids. Angew. Chem. Int. Ed. Engl. 17, 522-524 (1978).

48. Verley, A. \& Bölsing, F. Bestimmung des eugenols im nelkenöl. Ber. Dtsch. Chem. Ges. 34, 3359-3362 (1901).

49. Agarwal, M., Walia, S., Dhingra, S. \& Khambay, B. P. S. Insect growth inhibition, antifeedant and antifungal activity of compounds isolated/derived from Zingiber officinale Roscoe (ginger) rhizomes. Pest Manage. Sci. 57, 289-300 (2001).

50. Roman, B. I. et al. Feruloylbenzotriazole and Weinreb amide as bioinspired building blocks: a reactivity study towards O-, N-, S-, and C-Nucleophiles. Eur. J. Org. Chem. 2014, 2594-2611 (2014).

51. Poli, G. \& Giambastiani, G. An epiisopicropodophyllin aza analogue via palladium-catalyzed pseudo-domino cyclization. J. Org. Chem. 67, 9456-9459 (2002).

52. Wang, Z. et al. An efficient method for the selective iodination of $\alpha, \beta$-unsaturated ketones. Synthesis 2008, 3675-3681 (2008).

53. Enthaler, S. Practical one-pot synthesis of secondary amines by zinc-catalyzed reductive amination. Catal. Lett. 141, 55-61 (2011).

54. Ueda, T., Konishi, H. \& Manabe, K. Trichlorophenyl formate: highly reactive and easily accessible crystalline CO surrogate for palladium-catalyzed carbonylation of aryl/alkenyl halides and triflates. Org. Lett. 14, 5370-5373 (2012).

55. Stuart, D. R., Bertrand-Laperle, M., Burgess, K. M. \& Fagnou, K. Indole synthesis via rhodium catalyzed oxidative coupling of acetanilides and internal alkynes. J. Am. Chem. Soc. 130, 16474-16475 (2008).

56. Ladziata, U. et al. Synthesis, structure, and chemoselective reactivity of $N$-(2-iodylphenyl) acylamides: hypervalent iodine reagents bearing a pseudo-six-membered ring scaffold. Angew. Chem. Int. Ed. 44, 7127-7131 (2005).

57. Kondo, H. et al. Substituted benzoxazinorifamycin derivative. Japan patent JPH01207293 (A) (1989).

58. Plourde, G. L. 1-(4-Hydroxy-3-methoxyphenyl)-4,4-dimethyl-3-pentanone. Molbank 2003, M320 (2003).

59. Gorobets, E., Parvez, M., Derksen, D. J. \& Keay, B. A. Generation of benzyne species from diphenylphosphoryl derivatives: Simultaneous exchange of three functional groups. Chem. Eur. J. 22, 8479-8482 (2016).

60. Zeng, J. et al. Facile access to cis-2,6-disubstituted tetrahydropyrans by palladium-catalyzed decarboxylative allylation: total syntheses of ( \pm )-centrolobine and (+)-decytospolides A and B. Chem. Eur. J. 20, 405-409 (2014).

61. James, C. A. \& Snieckus, V. Combined directed remote metalation-transition metal catalyzed cross coupling strategies: the total synthesis of the aglycones of the gilvocarcins V, M, and E and arnottin I. J. Org. Chem. 74, 4080-4093 (2009).

62. Bartoli, G. et al. Alcohols and di-tert-butyl dicarbonate: how the nature of the Lewis acid catalyst may address the reaction to the synthesis of tert-butyl ethers. J. Org. Chem. 71, 9580-9588 (2006).

63. Kitayama, T., Isomori, S. \& Nakamura, K. Asymmetric synthesis of enantiomerically pure zingerols by lipase-catalyzed transesterification and efficient synthesis of their analogues. Tetrahedron: Asymmetry 24, 621-627 (2013).

64. Bosco, J. J., Raju, B. R. \& Saikia, A. K. Potassium fluoride assisted selective acetylation of alcohols with acetic acid. Synth. Commun. 34, 2849-2855 (2004).

65. Meiß, R., Kumar, K. \& Waldmann, H. Divergent gold(I)-catalyzed skeletal rearrangements of 1,7-enynes. Chem. Eur. J. 21, 13526-13530 (2015).

66. Yadav, J., Singh, V. K., Thirupathaiah, B. \& Reddy, A. B. First total synthesis and reassignment of absolute configuration of diosniponol A and B. Tetrahedron Lett. 55, 4427-4429 (2014).

67. Gembus, V. et al. Scaffold hopping strategy toward original pyrazolines as selective CB2 receptor ligands. Eur. J. Med. Chem. 58, 396-404 (2012).

68. Matsuzawa, S., Horiguchi, Y., Nakamura, E. \& Kuwajima, I. Chlorosilane-accelerated conjugate addition of catalytic and stoichiometric organocopper reagents. Tetrahedron 45, 349-362 (1989).

69. R: A Language and Environment for Statistical Computing (R Foundation for Statistical Computing, Vienna, Austria, 2018).

70. RStudio: Integrated Development Environment for R (RStudio, Inc., Boston, MA, 2016).

71. emmeans: Estimated Marginal Means, aka Least-Squares Means. R package version 1.3.1 (2018)

72. Wickham, H. ggplot2: Elegant Graphics for Data Analysis. (Springer-Verlag New York, 2016).

73. Wilhoit, R. C. \& Zwolinski, B. J. Physical and thermodynamic properties of aliphatic alcohols. J. Phys. Chem. Ref. Data 2 (1973).

\section{Acknowledgements}

The project New and improved fruit fly lures for border security and management (HG13047) is funded by the Hort Frontiers Fruit Fly Fund, part of the Hort Frontiers strategic partnership initiative developed by Hort Innovation, with co-investment from Macquarie University and contributions from the Australian Government. This research was supported by an Australian Government Research Training Program (RTP) Scholarship to B.L.H. We are grateful to Stefano De Faveri and Jodie Cheesman from the Queensland Department of Agriculture and Fisheries for advice and assistance in conducting the field trials; Brett McCahon from the Queensland Department of 
Agriculture and Fisheries for use of the Walkamin Research Facility; Geoff Dickinson for the use of the Malone Road site; and to Andrew King for the synthesis of several compounds. Aspects of this research have been facilitated by access to the Australian Proteome Analysis Facility supported under the Australian Government's National Collaborative Research Infrastructure Strategy (NCRIS).

\section{Author contributions}

B.L.H., S.J.P., J.F.J., I.M.J., and P.W.T. designed the experiments. B.L.H., S.J.P., J.E.R., and I.M.J. performed the experiments. B.L.H. analysed the data and wrote the manuscript. All authors revised the manuscript.

\section{Competing interests}

The authors declare no competing interests.

\section{Additional information}

Supplementary information is available for this paper at https://doi.org/10.1038/s41598-019-55778-4.

Correspondence and requests for materials should be addressed to I.M.J.

Reprints and permissions information is available at www.nature.com/reprints.

Publisher's note Springer Nature remains neutral with regard to jurisdictional claims in published maps and institutional affiliations.

(c) (i) Open Access This article is licensed under a Creative Commons Attribution 4.0 International License, which permits use, sharing, adaptation, distribution and reproduction in any medium or format, as long as you give appropriate credit to the original author(s) and the source, provide a link to the Creative Commons license, and indicate if changes were made. The images or other third party material in this article are included in the article's Creative Commons license, unless indicated otherwise in a credit line to the material. If material is not included in the article's Creative Commons license and your intended use is not permitted by statutory regulation or exceeds the permitted use, you will need to obtain permission directly from the copyright holder. To view a copy of this license, visit http://creativecommons.org/licenses/by/4.0/.

(C) The Author(s) 2019 